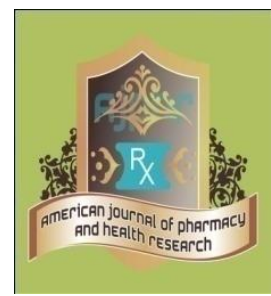

\title{
Formulation and Evaluation Of Colon Targeted Drug Delivery System Of Edotolac Tablets
}

\author{
K.S. Srilatha ${ }^{1 *}$ Beulah Milton ${ }^{2}$ Dili RAJ Biswas ${ }^{1}$ \\ 1. Department of Pharmaceutics, RR college of Pharmacy Bangalore 560090. \\ 2. Department of Pharmacy practice, RR college of Pharmacy Bangalore 560090.
}

\begin{abstract}
Etodolac is used for the management of rheumatoid osteoarthritis. The site of absorption of Etodolac is in the whole GI tract and has a long half-life of $7 \pm 4 \mathrm{hrs}$. The aim of the study was to develop colon targeted compression coated tablets of Etodolac using HPMC as swellable, timecontrolled polymer, Eudragit S 100 as a coating polymer guar gum and chitosan as carriers in the treatment of Osteoarthritis. All the formulations (F1 to F5) were evaluated for the physicochemical parameters and were subjected to in vitro drug release studies. The amount of Etodolac released from tablets at different time intervals was estimated by UV spectrophotometer. The formulation F3 released 95.24\% of Etodolac. The results of the study showed that formulation F3 is most likely to provide targeting of Etodolac for local action in the colon owing to its minimal release of the drug in the first $5 \mathrm{~h}$. The most satisfactory formulation was stable during stability studies conducted for 60 days as per ICH guidelines. It showed no significant changes in the physicochemical parameters, in vitro release pattern. The studies confirmed that, the designed formulation could be used potentially for colon delivery by controlling drug release in stomach and the small intestine.
\end{abstract}

Keywords: Etodolac, rheumatoid osteoarthritis, HPMC and colon targeted. 


\section{INTRODUCTION}

The oral route of drug administration is the most convenient and important method of administering drugs for systemic effect. Nearly $50 \%$ of the drug delivery systems available in the market are oral D.D.S and these systems have more advantages due to patient acceptance and ease of administration. Colonic drug delivery has gained increased importance not just for the delivery of the drugs for the treatment of local diseases associated with the colon like Crohn's disease, ulcerative colitis, irritable bowel syndrome and constipation but also for the systemic delivery of proteins, therapeutic peptides, antiasthmatic drugs, antihypertensive drugs and antidiabetic agents. There are various methods or techniques through which colon drug targeting can be achieved, for example, formation of prodrug, coating with $\mathrm{pH}$ sensitive polymers, coating with biodegradable polymers, designing formulations using polysaccharides, timed released systems, pressure-controlled drug delivery systems, osmotic pressure-controlled systems. It is a serious drawback in conditions when localized delivery of drug in to colon is required as drug need to be protected from the hostile environment of upper GIT. Targeted drug delivery in to the colon is highly desirable for local treatment of variety of bowels diseases such as ulcerative colitis, cirrhosis and colonic cancer. Coating of the drugs with $\mathrm{pH}$-sensitive polymers provides simple approach for colon specific drug delivery.

\section{Compressed Core Coated Tablets}

It is a system in which the entire surface of an inner core is totally surrounded by the coat these coats prevent drug release from the core until the polymeric or drug coat is fully eroded, dissolved or removed. It is simple and unique technology used to provide tablets with a programmable lag phase, followed by a rapid, or rate-controlled drug release. Release of drug depends upon the coating layer and core composition. It has a solvent-free coating and facilitates manufacturing process. It can be used to deliver one or more drugs.

It is one of the approaches which combine the features of both controlled release tablet and instant release tablet in one dosage form. It functions like sugar-coated or film-coated tablets in which the coating may cover a bitter substance, conceal an unpleasant or mottled appearance. Provide a barrier for a substance irritating to the stomach or single inactivated by gastric juice. This gives a far more accurate dose than in the case with sugar coating.

\section{Etodolac}

Etodolac is a member of the pyran carboxylic acid group of non steroidal anti-inflammatory drugs (NSAIDs). Etodolac is indicated for acute and long-term management of signs and 
symptoms of osteoarthritis and rheumatoid arthritis, as well as for the management of pain.

\section{MATERIALS AND METHOD}

Etodolac was obtained from Cadila health care 1td, guar gum, eudragit S 100, chitosan, HPMC, lactose, starch, magnesium sterate and all other reagents and solvents were of analytical grade.

\section{ANALYTICAL METHOD USED IN THE DETERMINATION OF ETODOLAC: \\ Determination of $\lambda_{\max }$ using $\mathrm{pH} 6.8$ phosphate buffer.}

Absorbance maximum $(\lambda \max )$ for a drug was determined in $\mathrm{pH} 6.8$ phosphate buffer. Accurately weighed $10 \mathrm{mg}$ of pure Etodolac was transferred into $100 \mathrm{ml}$ volumetric flask. The drug was then dissolved with $10 \mathrm{ml}$ of methanol and diluted up to the mark with buffer to obtain a concentration of $100 \mu \mathrm{g} / \mathrm{ml}$ as stock solution. From the stock solution aliquot was withdrawn to obtain a concentration of $5 \mu \mathrm{g} / \mathrm{ml}$ and scanned over the wavelength range of $400 \mathrm{~nm}$ to $200 \mathrm{~nm}$ using UV-spectrophotometer against same dilutions as blank. The spectrum of absorbance versus wavelength was recorded and analyzed for the absorbance maximum ( $\lambda$ max) and its wavelength.

\section{Standard calibration curve of Etodolac in phosphate buffer pH 7.4}

$100 \mathrm{mg}$ of Etodolac was accurately weighed and dissolved with $10 \mathrm{ml}$ of methanol in a $100 \mathrm{ml}$ volumetric flask and made up to volume using phosphate buffer $\mathrm{pH}$ 7.4. Stock solution of Etodolac was subsequently diluted to a series of dilutions containing 2, 4, 6, 8 and $10 \mu \mathrm{g} / \mathrm{ml}$ of solution using phosphate buffer $\mathrm{pH}$ 7.4. The Absorbance of these solutions was measured in UVVisible spectrophotometer at $274 \mathrm{~nm}$ against same dilutions as blank. The graph of absorbance $\mathrm{v} / \mathrm{s}$ concentration $(\mu \mathrm{g} / \mathrm{ml})$ was plotted and data was subjected to linear regression analysis.

\section{PRE-FORMULATION STUDIES}

\section{Compatibility study}

Compatibility of the drug with the excipients is determined by subjecting the physical mixture of the drug and the polymers of the main formulation to infrared absorption spectral analysis (FTIR). Any changes in chemical composition of the drug after combining it with the polymers were investigated with I.R. spectral analysis.

\section{Procedure:}

Weighed amount of drug (3 mg) was mixed with 100mg of potassium bromide (dried at 40$50^{\circ} \mathrm{C}$ ). The mixture was taken and compressed under 10-ton pressure in a hydraulic press to form a transparent pellet. The pellet was scanned by IR spectrophotometer.

Similar procedure is followed for all relevant excipients used.

\section{Formulation and Development of Etodolac Tablets}


Table 1: Composition of Core Tablets of Etodolac

\begin{tabular}{llllll}
\hline Ingredients (mg) & F1 & F2 & F3 & F4 & F5 \\
\hline Etodolac & 400 & 400 & 400 & 400 & 400 \\
Guar gum & 25 & 50 & 75 & 100 & - \\
Chitosan & 75 & 50 & 25 & - & 100 \\
Lactose & 20 & 20 & 20 & 20 & 20 \\
Starch & 20 & 20 & 20 & 20 & 20 \\
Mg-sterate & 10 & 10 & 10 & 10 & 10 \\
Total & 550 & 550 & 550 & 550 & 550 \\
\hline
\end{tabular}

Table 2: Composition of compression coated tablets of Etodolac

\begin{tabular}{llllll}
\hline Ingredients(mg) & F1 & F2 & F3 & F4 & F5 \\
\hline Core tablet & 550 & 550 & 550 & 550 & 550 \\
Eudragit & 150 & 120 & 90 & 60 & 30 \\
HPMC & 30 & 60 & 90 & 120 & 150 \\
MCC & 10 & 10 & 10 & 10 & 10 \\
MgS & 8 & 8 & 8 & 8 & 8 \\
Talc & 2 & 2 & 2 & 2 & 2 \\
Total & 700 & 700 & 700 & 700 & 700 \\
\hline
\end{tabular}

FORMULATION OF ETODOLAC CORE TABLET Wet Granulation method:

Weighing and mixing

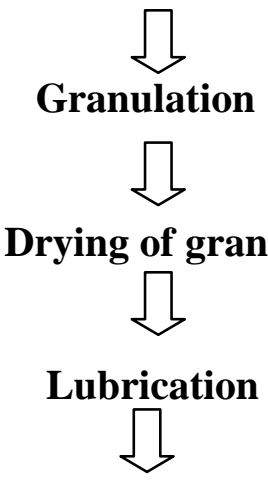

Compression

Figure 1: Flow chart of wet granulation method

FORMULATION OF ETODOLAC COMPRESSION COATED TABLETS

\section{Method of preparation}

- Firstly, core tablet is formulated which is small in size.

- Then for the upper coating, large size punches are used.

- Half amount of coating material is placed in die cavity.

- Then carefully placed a core tablet on it.

- After that remaining half amount of coating material is taken.

- And finally, the tablet is compressed as compression coated tablet. 

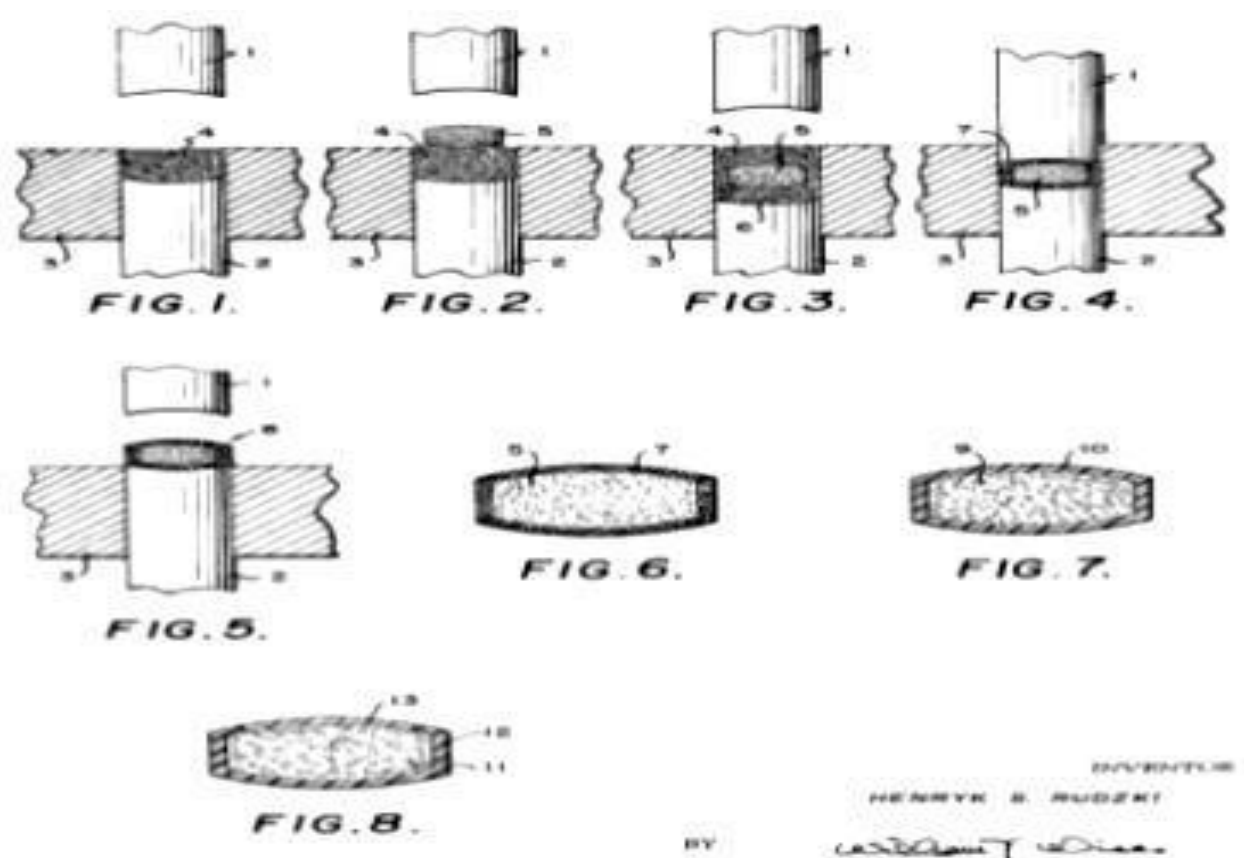

Figure 2: compression coating technique

All ingredients are weighed accurately and passed through 40 no sieves. All ingredients except magnesium stearate was transferred in to the motor and mixed thoroughly for 5 min to obtain a uniform mixed powder and blend homogenously for $15 \mathrm{~min}$ by triturating with the help of pestle. The above blend mixture was granulated with $10 \% \mathrm{w} / \mathrm{v}$ starch paste till a coherent mass was formed and passed through mesh no. 10 to form granules. The collected granules were dried at $40{ }^{\circ} \mathrm{C}$. and passed through sieve 20 . Granules were lubricated by blending with magnesium stearate and evaluated for pre compression parameter and then subjected for tablet compression.

\section{Pre-compression parameters}

\section{Angle of Repose:}

The angle of repose is the constant, three-dimension angle (relative to horizontal base) assumed by a cone like pile of material formed by any of several different methods. When the angle of repose exceeds 50degrees, the flow is rarely accepted for manufacturing purpose.

\section{Bulk Density:}

The bulk density was determined by transferring the accurately weighed sample of powder to the graduate cylinder. The initial volume and weight were noted. Ratio of weight of the sample was calculated by using the following formula.

$$
\text { Bulk Density =Mass /Bulk volume. }
$$

\section{Tapped Density:}

Weighed powder sample was transferring to a graduated cylinder and was placed on the tap 
density apparatus, was operated for fixed number of taps (100). The tapped density was determined by the following formula.

Tapped Density =Mass/Tapped volume.

\section{Percentage compressibility:}

Based on the apparent bulk density and tapped density, the percentage compressibility of the bulk drug was determined by the following formula

$\%$ Compressibility=Tapped density-Bulk density $\times 100 /$ Tapped density.

\section{Hauser's Ratio:}

It is measured by the tapped density to bulk density.

\section{Hauser's Ratio= Tapped density/Bulk density}

\section{POST COMPRESSION PARAMETERS}

\section{Tablet thickness:}

Randomly 5 tablets were taken from each formulation trial batch and their thickness was determined by using screw gauge.

\section{Weight variation test:}

20 tablets were randomly selected from each formulation trial batch and their average weight was calculated using digital balance. Individual weight of each tablet was also calculated using the same and compared with the average weight.

\section{Measurement of tablet hardness:}

Hardness of 10 tablets was found using Monsanto hardness tester, mean and standard deviation were computed and reported. It is expressed in $\mathrm{kg} / \mathrm{cm}^{2}$.

\section{Friability:}

10 tablets were weighed and placed in Roche friabilator where the tablets were exposed to rolling and repeated shocks resulting from free falls within the apparatus. The Friabilator was operated at $25 \mathrm{rpm}$ for 4 mins. After 100 revolutions, tablets are removed, deducted and weighed again. The friability was determined as the percentage loss in weight of the tablets.

\section{Content Uniformity}

Crush four (4) tablets and take average weight of tablet powder equivalent to $10 \mathrm{mg}$ of Etodolac and dissolve in $100 \mathrm{ml}$ of $\mathrm{pH} 6.8$ phosphate buffer. Tablets was allowed to dissolve in the solution and $5 \mathrm{ml}$ of filtrate was dilute to $50 \mathrm{ml}$ with the same buffer and analysed spectrophotometrically at $274 \mathrm{~nm}$.

\section{In-vitro dissolution studies}

In-vitro dissolution study was performed by using USP Type II Apparatus (Basket type) 
[Electrolab (ETC-11L) Tablet Dissolution Tester] at $100 \mathrm{rpm}$ for $2 \mathrm{~h}$ in $0.1 \mathrm{~N} \mathrm{HCl}(900 \mathrm{ml})$. Then the dissolution medium was replaced with $\mathrm{pH} 7.4$ phosphate buffer $(900 \mathrm{ml})$ and tested for $3 \mathrm{~h}$ as the average transit time of small intestine is $3 \mathrm{~h}$. After $5 \mathrm{~h}$, the dissolution medium was replaced with $\mathrm{pH} 6.8$ phosphate buffer and tested for next $10 \mathrm{~h}$. At the end of the time period 5 $\mathrm{ml}$ of the sample were taken and analyzed for Etodolac content as described previously. $5 \mathrm{ml}$ of filtrate was diluted to $50 \mathrm{ml}$ with the same buffer and analysed spectrophotometrically at $274 \mathrm{~nm}$.

\section{Zero order kinetics}

Drug dissolution from pharmaceutical dosage forms that do not disaggregate and release the drug slowly (assuming that area does not change and no equilibrium conditions are obtained) can be represented by the following equation.

$$
\mathbf{W}_{\mathbf{0}}-\mathbf{W}_{\mathbf{t}}=\mathbf{K}_{\mathbf{0}} \mathbf{t}
$$

Where $\mathbf{W}_{\mathbf{0}}$ is the initial amount of drug in the pharmaceutical dosage form, $\mathbf{W}_{\mathbf{t}}$ is the amount of drug in the pharmaceutical dosage form at time $\mathrm{t}$ and $\mathrm{k}$ is proportionality constant.

\section{First order kinetics}

This type of model to analyse drug dissolution study was first proposed by Gibaldi and Feldman and later by Wagner. The relation expressing this model:

\section{$\log Q_{t}=\log Q_{0}+K_{1} t / 2.303$}

Where $Q_{t}$ is the amount of drug released in time $t, Q_{0}$ is initial amount of drug in the solution and $\mathrm{K}_{1}$ is the first order release rate constant.

\section{Korsmeyer Peppas model}

Korsmeyer developed a simple semi empirical model, relating exponentially the drug release to the elapsed time $(\mathrm{t})$.

$$
\mathbf{Q}_{t} / \mathbf{Q}_{\alpha}=\mathbf{K}_{\mathbf{k}} \mathbf{t}^{\mathbf{n}}
$$

Where $K_{k}$ is a constant incorporating structural and geometric characteristic of the drug dosage form and $\mathrm{n}$ is the release exponent, indicative of the drug release mechanism.

\section{Table 2: kinetic model}

\begin{tabular}{lll}
\hline Release exponent (n) & Drug transport mechanism & Rate as a function of time \\
\hline 0.5 & Fickian diffusion & $\mathrm{t}^{-0.5}$ \\
$0.5<\mathrm{n}<1.0$ & Anomalous transport & $\mathrm{t}^{\mathrm{n}-1}$ \\
1.0 & Case-II transport & Zero-order release \\
Higher than 1.0 & Super Case-II transport & $\mathrm{t}^{\mathrm{n}-1}$ \\
\hline
\end{tabular}

\section{Higuchi Model}

This is the most widely used model to describe drug release from pharmaceutical matrices. A linear relationship between the square root of time versus concentration indicates that the drug 
release follows strict Fickian diffusion.

$Q_{t}=K_{H} t^{1 / 2}$

Where

$\mathrm{Q}_{\mathrm{t}}=$ the amount of drug released at time $\mathrm{t}$ and

$\mathrm{K}_{\mathrm{H}}=$ the Higuchi release rate

RESULTS AND DISCUSSION

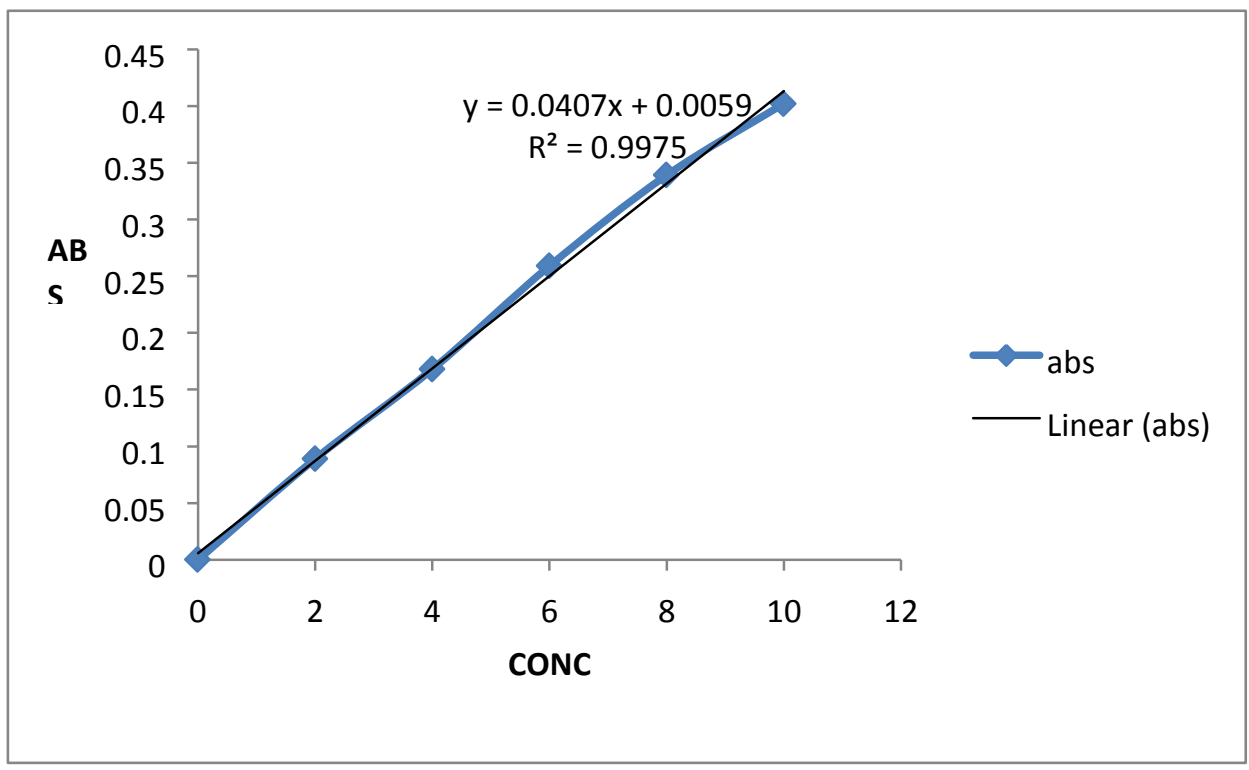

Figure 3: Standard calibration curve for Etodolac in phosphate buffer pH 7.4

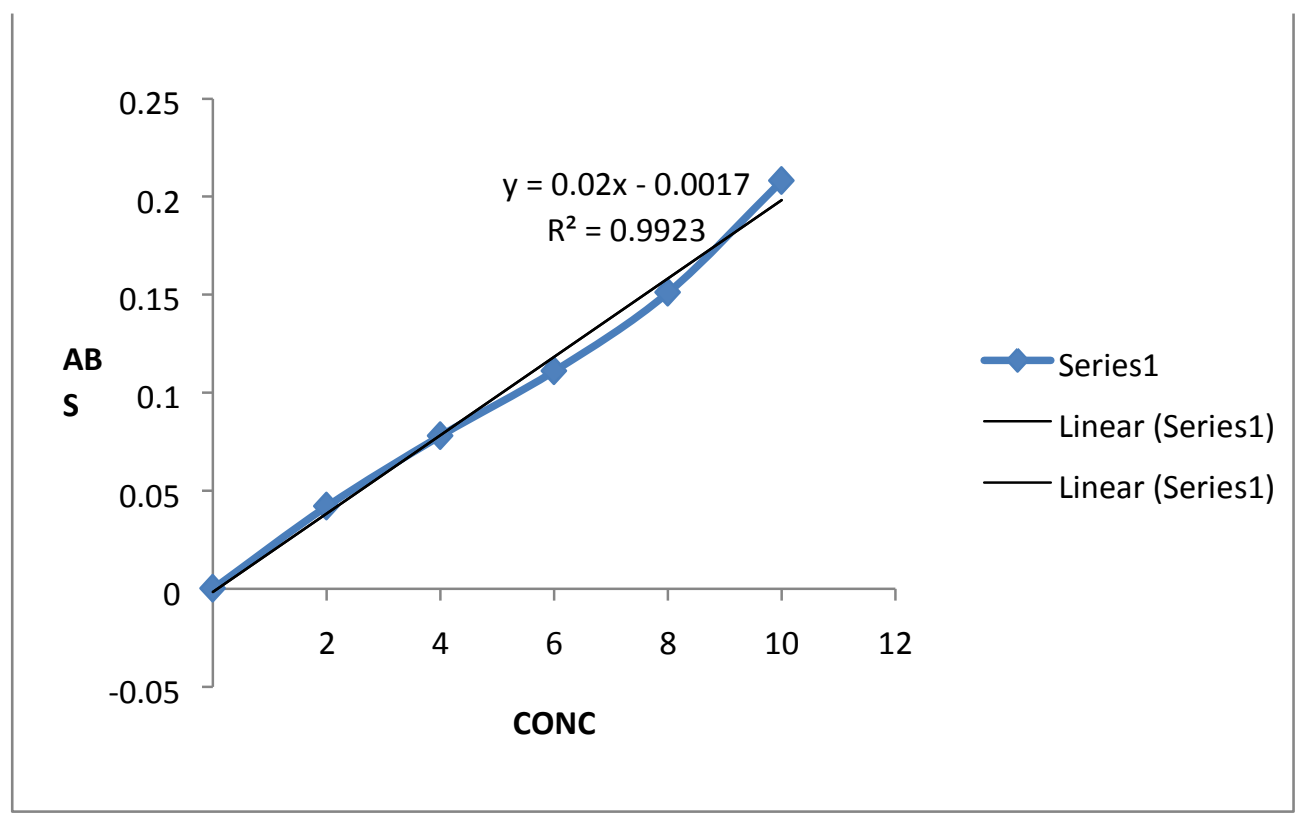

Figure 4: Standard calibration curve of Etodolac in phosphate buffer $6.8 \mathrm{pH}$ 


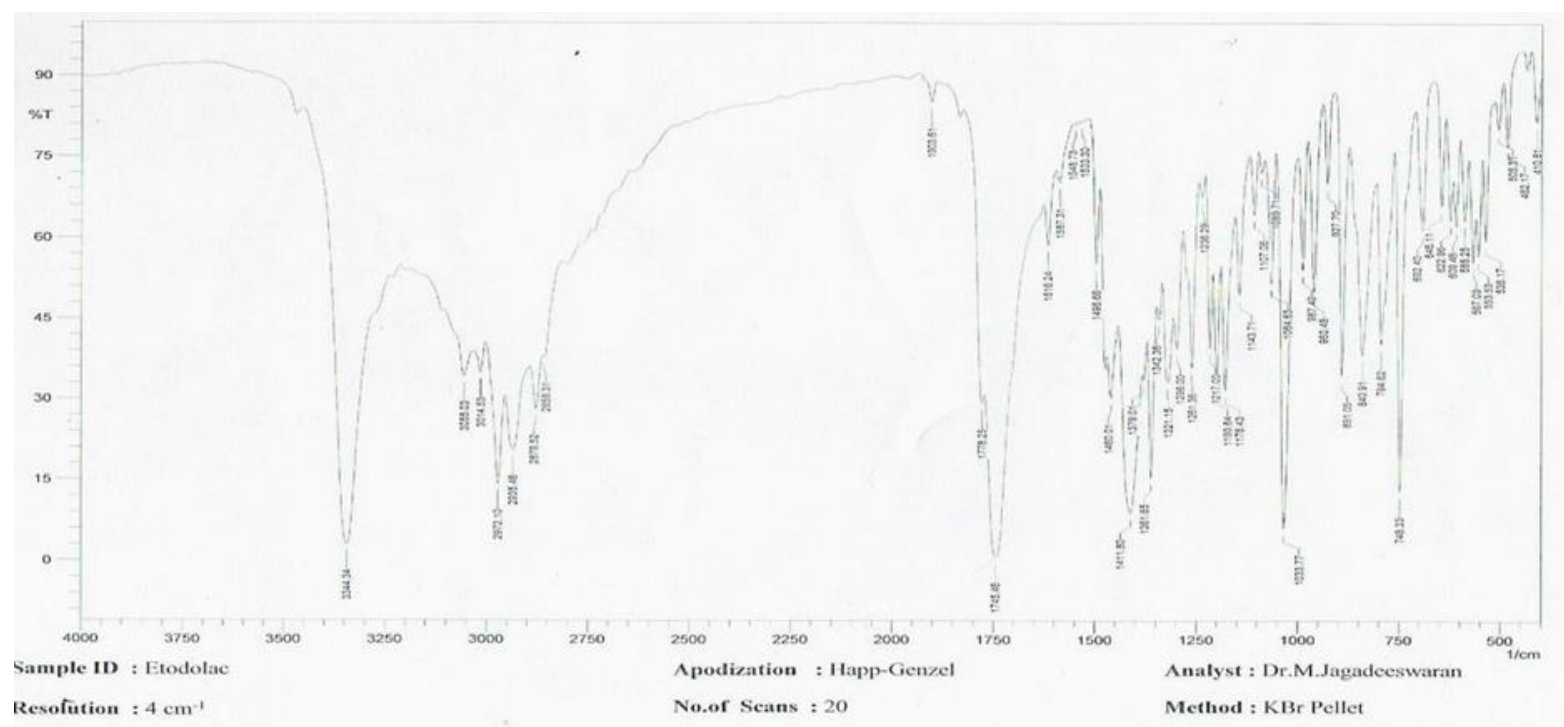

Figure 5: FTIR spectrum of pure Etodolac

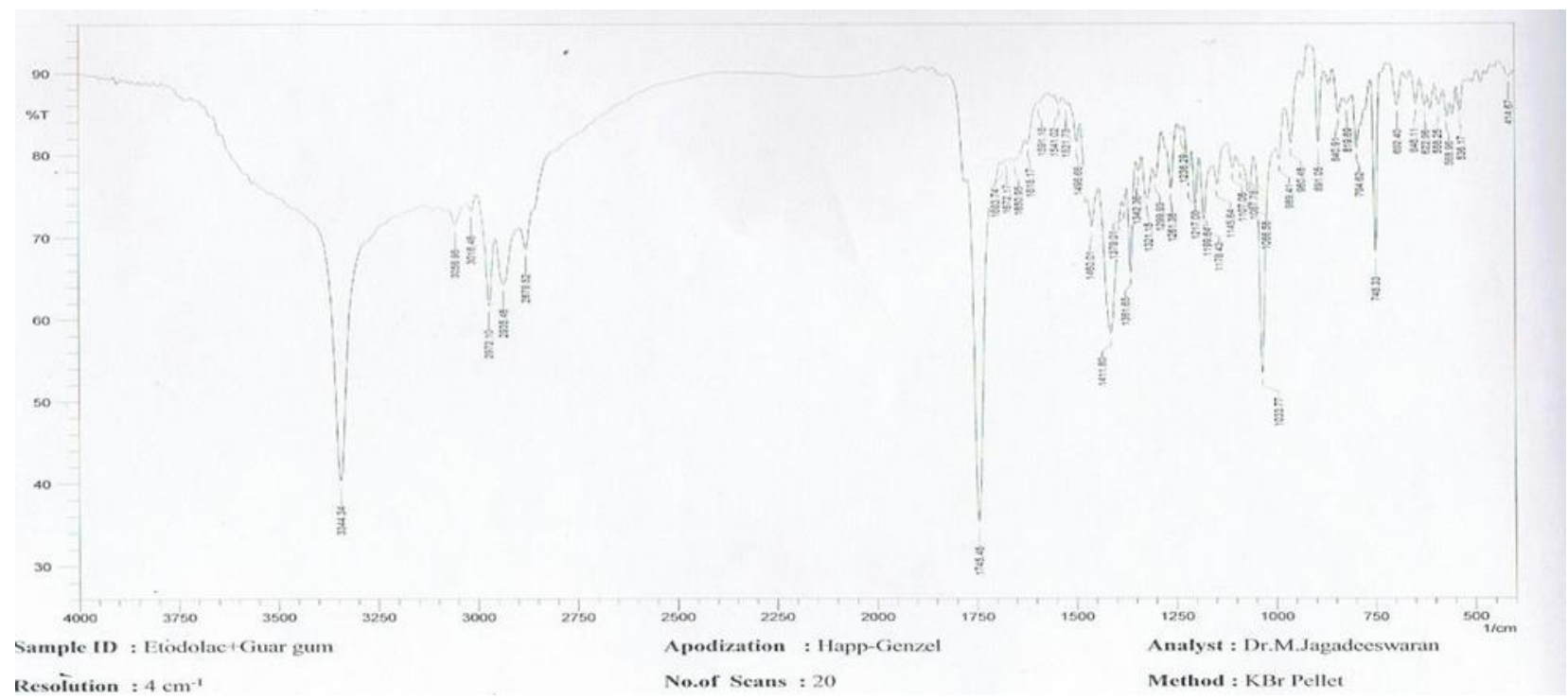

Figure 6: FTIR spectrum of Etodolac with polymers

\section{EVALUATION OF COLON TARGETED ETODOLAC TABLETS}

\section{Pre compression evaluation parameter}

Table 3: Pre-Compression Parameter results

\begin{tabular}{llllll}
\hline Formulation & F1 & F2 & F3 & F4 & F5 \\
\hline Bulk density g/cm & $0.41 \pm 0.016$ & $0.45 \pm 0.03$ & $0.378 \pm 0.055$ & $0.350 \pm 0.036$ & $0.40 \pm 0.027$ \\
Tapped density g/cm & $0.51 \pm 0.012$ & $0.48 \pm 0.06$ & $0.472 \pm 0.03$ & $0.406 \pm 0.07$ & $0.45 \pm 0.05$ \\
Angle of repose $\left(^{\circ}\right)$ & $18 \pm 0.383$ & $19 \pm 0.370$ & $18 \pm 0.212$ & $19.3 \pm 0.41$ & $18.5 \pm 0.296$ \\
Carr's index\% & $19.60 \pm 0.185$ & $6.25 \pm 0.153$ & $20 \pm 0.182$ & $13.79 \pm 0.22$ & $11.11 \pm 0.24$ \\
Hausner's ratio & $1.24 \pm 0.0176$ & $1.06 \pm 0.099$ & $1.24 \pm 0.0101$ & $1.16 \pm 0.0172$ & $1.125 \pm 0.0102$ \\
\hline
\end{tabular}


Table 4: Data for post compression studies of the prepared formulation for core tablet

\begin{tabular}{llllll}
\hline Parameters & F1 & F2 & F3 & F4 & F5 \\
\hline Thickness $(\mathrm{mm})$ & $3.831 \pm 0.0516$ & $3.830 \pm 0.0527$ & $3.831 \pm 0.0483$ & $3.825 \pm 0.0632$ & $3.822 \pm 0.0707$ \\
Hardness $\left(\mathrm{kg} / \mathrm{cm}^{2}\right)$ & $5.836 \pm 0.5851$ & $5.96 \pm 0.1476$ & $5.88 \pm 0.5782$ & $5.90 \pm 0.1989$ & $5.83 \pm 0.5731$ \\
Friability $(\%)$ & $0.31 \% \pm 0.0730$ & $0.39 \% \pm 0.0312$ & $0.45 \% \pm 0.0115$ & $0.30 \% \pm 0.0422$ & $0.28 \% \pm 0.0456$ \\
Weight variation $(\mathrm{mg})$ & $547.66 \pm 0.062 \%$ & $549.66 \pm 0.08 \%$ & $550.66 \pm 0.061 \%$ & $547 \pm 0.182 \%$ & $548 \pm 0.183 \%$ \\
Drug content $(\%)$ & $95.01 \% \pm 0.2435$ & $90 \% \pm 0.31$ & $99.86 \% \pm 0.3107$ & $90.03 \% \pm 0.3094$ & $94.5 \% \pm 0.3573$ \\
\hline
\end{tabular}

Post compression studies compressed coated tablet

Table 5: Data for post compression studies of the prepared formulation for compressed coated tablet

\begin{tabular}{llllll}
\hline Parameters & F1 & F2 & F3 & F4 & F5 \\
\hline Thickness $(\mathrm{mm})$ & $5.12 \pm 0.0568$ & $5.18 \pm 0.0675$ & $5.17 \pm 0.0516$ & $5.14 \pm 0.0632$ & $5.16 \pm 0.0675$ \\
Hardness $\left(\mathrm{kg} / \mathrm{cm}^{2}\right)$ & $6.4 \pm 0.2983$ & $6.5 \pm 0.3464$ & $6.7 \pm 0.2781$ & $6.8 \pm 0.2635$ & $6.8 \pm 0.1792$ \\
Friability $(\%)$ & $0.24 \% \pm 0.1009$ & $0.34 \% \pm 0.1299$ & $0.38 \% \pm 0.1229$ & $0.2 \% \pm 0.1010$ & $0.24 \% \pm 0.1348$ \\
Weight variation $(\mathrm{mg})$ & $748.3 \pm 0.04 \%$ & $750 \pm 0.1 \%$ & $750.6 \pm 0.05 \%$ & $747.3 \pm 0.04 \%$ & $748.6 \pm 0.08 \%$ \\
Drug content $(\%)$ & $94.53 \% \pm 0.135$ & $89 \% \pm 0.117$ & $95 \% \pm 0.271$ & $90.5 \% \pm 0.309$ & $91.02 \% \pm 0.067$ \\
\hline
\end{tabular}

\section{In Vitro Drug Release Study of Formulations}

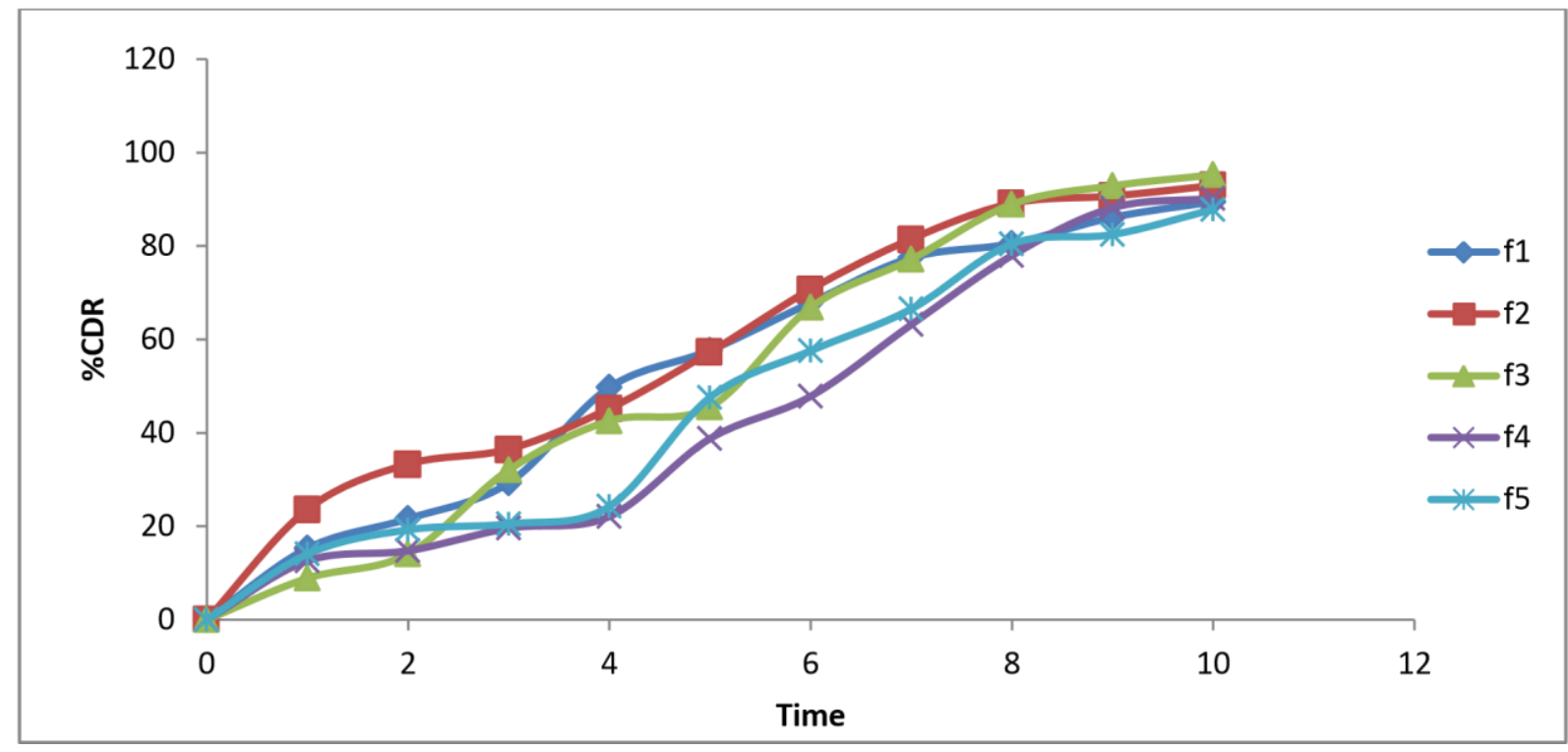

Figure 7: In vitro drug release study of formulations (F1- F5) in phosphate buffer (pH 6.8)

Table 6: Kinetics modelling data

\begin{tabular}{|c|c|c|c|c|c|}
\hline $\begin{array}{l}\text { Formulation } \\
\text { code }\end{array}$ & $\begin{array}{l}\text { Zero } \\
\text { order } \\
\quad\left(\mathbf{r}^{2}\right)\end{array}$ & $\begin{array}{l}\text { First } \\
\text { order } \\
\left(\mathbf{r}^{2}\right)\end{array}$ & $\begin{array}{l}\text { Higuchi } \\
\qquad\left(\mathbf{r}^{2}\right)\end{array}$ & $\begin{array}{l}\text { Krosn } \\
\text { peppa } \\
\left(\mathbf{r}^{2}\right)\end{array}$ & $\begin{array}{l}\text { neyer- } \\
\text { S } \\
\text { (n) }\end{array}$ \\
\hline $\mathrm{F} 1$ & 0.97 & 0.67 & 0.98 & 0.98 & 0.71 \\
\hline $\mathrm{F} 2$ & 0.95 & 0.59 & 0.98 & 0.98 & 0.70 \\
\hline F3 & 0.95 & 0.80 & 0.99 & 0.92 & 0.73 \\
\hline F4 & 0.95 & 0.77 & 0.92 & 0.94 & 0.69 \\
\hline F5 & 0.96 & 0.73 & 0.91 & 0.96 & 0.69 \\
\hline
\end{tabular}




\section{CONCLUSION}

The present investigation was aimed to develop novel oral colon targeted compression coated tablet formulations of Etodolac for safe and effective therapy of rheumatoid arthritis by using Eudragit S 100 and HPMC mixture as a coating material the pre-formulation studies and post compression studies of Etodolac complied with IP standards. The FTIR spectra revealed that, there was no interaction between polymer and drug polymers used were compatible with Etodolac. In vitro drug release kinetic study revealed that Etodolac tablet formulation F1 to F5 release drug with Higuchi kinetics, whereas tablet formulation F4 and F5 release drug with Zero order kinetic. From the korsmeyer-peppas model, it revealed that the drug release profile tablet formulation F1 to F6 follow non-Fickian transport mechanism. The susceptibility of the core tablet to the enzymatic action of colonic bacteria was assessed by performing the drug release studies in medium containing $\mathrm{pH} 6.8$ phosphate buffer using guar gum and Chitosan mixture in ratio $(3: 1)$ as carriers. In conclusion, the core tablets compression-coated with Eudragit S 100 : HPMC as a coat material in the ratio (1:1) released only $6 \%$ of drug in the physiological environment of stomach and small intestine and released more than $95 \%$ of the drug in the target area i.e. physiological environment of colon Thus, based on these results, the tablets containing optimum proportion of Eudragit S 100:HPMC mixture (1:1) is most likely to target Etodolac to the colon without being released significantly in stomach and small intestine.

\section{REFERENCE}

1. Barbara L, Teresa C, Federica B, Isabella O, Vittorio Z, "pH-sensitive polymeric physical- mixture for possible site specific delivery of ibuprofen” Eur J Pharm Biopharm. 2003; 55:199- 202.

2. Lachman L, Lieberman HA, Kanig JL, "The theory and practice of industrial pharmacy.3rd edition. Bombay" Varghese publishing house: Hind Rajasthan building; 1991:293.

3. Antonin KH, Rak R, Beick PR, Schenker U, Hastewell J, Fox R, "The absorption of human calcitonin from the transverse colon of man” Int J Pharm.1996; 130: 33-39.

4. Tozaki H, Komoike J, Tada C, Maruyama T, Terabe A, Suzuki T, Yamamoto A, Muranishi S, "Chitosan capsules for colon specific drug delivery" Improvement of insulin absorption from the rat colon. J Pharm Sci 1997; 86(9) 1016-1021.

5. Van-den GM, Kinget R, "Oral colon-specific drug delivery: a review. Drug Delivery" 1995; 2: 81-93.

6. Rama Prasad Y, Krishnaiah Y, Satyanarayana S, "In vitro evaluation of guar gum as a carrier for colon-specific drug delivery” J Controlled Release 1998; 51: 281-287. 
7. Chate et. al/ Advances in Applied and Pharmaceutical Sciences Journal 1 (2) 2016:8-20

8. Rohini P, MV Nagabhushanam, and SDVS KiranKadali. Enhancement of the Dissolution Rate and Bioavailability of Etodolac in Solid Dispersions by Cyclodextrin Complexes. Res. J. of Pharm. Bio and Chem. Sci. Nov-Dec.2014;5(6):7-23.

9. Drug bank of Etodolac. [Internet]. 13 Jun 2005. http://www.drugbank.ca/drugs/DB00749.

10. Lodine SR Patient Information Leaflet (PIL) [Internet].18Sep2014. https://www.medicines.org.uk/emc/medicine/3657.

11. Y.R Sharma. Elementary organic spectroscopy, principles and chemical application. 1st ed. S. chand publication; 2001. p. 81-82.

12. Krishnaiah.Y.S.R, Bhaskar Reddy.P.R, Satyanarayana.V, Karthikeyan.R.S. Int J Pharm, 2002; 236(2):43-55.

13. Wu.B, Chen.Z, Wei.X, Sun.N, Lu.Y, Wu.W.Eur J Pharm Biopharm 2007; 67: 707-714.

14. Xinmuing L, Qingshen S, Huajie W, Lei Z, Jin-Ye W, Microspheres of Corn protein, zein, for an ivermectin drug delivery system Biomaterials, 2005; 26:109- 115.

15. Klaus F, David.W.F, Analytical Profiles of Drug Substances- Ivermectin, Academic Press-Elsevier, 1st Ed, Vol 17, New Delhi; 2005:156-184.

16. Fatima.L, Asghar.A, Chandran.S. J Pharm Pharmaceut Sci 2006; 9(3):327-338.

17. Gautam S, Review: In vitro drug release characterization models, international journal of Pharmaceutical studies and research, January 2011; 2: 77-84.

18. Hussain L, Kinetic modeling and dissolution profiles comparison: An overview, Int.J.Pharm Bio Sci., January 2013; 4(1): 728-737.

19. Paulo C, Modeling and comparison of dissolution profile, European journal of Pharmaceutical sciences, 2001; 13: 123-133.

20. Ramteke K.H., Mathematical models of drug dissolution: a review, sch. Acad.J.Pharm, 2014; 3(5): 388-396.

21. Gautam S, Review: In vitro drug release characterization models, international journal of Pharmaceutical studies and research, January 2011; 2: 77-84.

AJPHR is

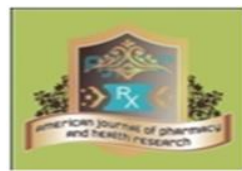

Peer-reviewed

monthly

Rapid publication

Submit your next manuscript at

editor@ajphr.com / editor.ajphr@gmail.com 